\title{
Establishment of 5-Fluorouracil-resistant canine mammary tumor cell line
}

\author{
B. Zhou, D. Zhang, SM. Pei, H. Zhang, HC. Du, YP. Jin, DG. Lin \\ The Clinical Department, College of Veterinary Medicine, \\ China Agricultural University, Beijing, 100193, China
}

\begin{abstract}
Canine mammary tumors are the most common neoplasms in intact female dogs. The surgery cannot always solve the problem, chemotherapy are recommend to these patients. However, chemotherapy could always fail because of multidrug resistance (MDR). Through stepwise increasing 5-Fluorouracil (5-FU) concentration in the culture medium, a 5-FU-resistant canine mammary tumor cell line CMT7364/5-FU was established to disclose the molecular mechanism of the drug resistance. Cell morphology, cell sensitivity to drugs, growth curves, expression of proteins, and chemo-sensitivity in vivo were compared between the parental cell line and resistant cell line. As compared it to its parental cell line (CMT7364), CMT7364/5-FU showed different morphology, cross-resistant to other chemo-drugs and a prolonged population doubling time (PDT). The drug efflux pump proteins (ABCB1 and ABCG2) in CMT7364/5-FU were up-regulated. In vivo, the similar result revealed that CMT7364/5-FU cell line was more resistant to 5-FU. In conclusion, a 5-FU-resistant canine mammary tumor cell line (CMT7364/5-FU) was successfully established, it can serve as a good model for researching the mechanism of MDR and screening effective agents to reverse drug resistance.
\end{abstract}

Key words: canine; mammary tumor, 5-Fluorouracil, multiple drug resistance, ABC proteins

\section{Introduction}

Mammary gland carcinomas are the most common neoplasms in both women and intact female dogs. The major treatment in clinic is surgery. As most of the neoplasms are malignant, surgery cannot always solve the problem. In order to improve the quality and quantity of life, chemotherapy is recommended to these patients. Unfortunately, chemotherapy could fail in many ways. One of the most significant reasons is the effect of multidrug resistance (MDR) (Krol et al. 2014). MDR means that when cancer cells are resistant to one kind of drug, they could also acquire resistance to other kinds of drugs (Choi 2005). For many mechanisms the cancer cells can be resistant to chemotherapy, but the most important one is the expression of the ATP-binding cassette $(A B C)$ superfamily proteins, which are the largest group of transmembrane proteins. These proteins can protect the cells from the chemotherapy by pumping the drugs out of cells after consuming ATP (Sosnik 2013). Many studies have shown that drug resistance in dogs was also due to the expression of ABC proteins, such as P-glycoprotein (PGP), breast cancer resistance protein (BCRP), multidrug resistance-associated protein 1 (MRP1) and multidrug resistance-

Correspondence to: YP. Jin, e-mail: yipengjin@sina.com, D. Lin, e-mail: csamalin@163.com 
-associated protein 3 (MRP3) (Nakaichi et al. 2007, Honscha et al. 2009, Pawlowski et al. 2013, Tomiyasu et al. 2014).

5-Fluorouracil (5-FU) is an analogue of uracil with a fluorine atom at the C-5 position in place of hydrogen. It could enter the cell rapidly using the same facilitated transport mechanism as uracil does. 5-FU is then converted intracellularly to several active metabolites, which might disrupt the RNA synthesis and the action of thymidylate synthase (TS). 5-FU has been used to treat various cancers and accepted worldwide as a first-line anticancer drug for breast cancer chemotherapy (Karayannopoulou et al. 2001, Longley et al. 2003). In the research of human cancer, some studies have been done on the mechanism of 5-FU resistance in several cancers (Pratt et al. 2005, Oguri et al. 2007).

Till now, many 5-FU resistant cell lines of human cancer have been reported, whereas few for dogs (Shin et al. 2005). In this study, to explore the underlying mechanism of drug resistance in canine, a 5-FU-resistant canine mammary tumor cell line was established and its biological characteristics were verified.

\section{Materials and Methods}

\section{Cell line and cell culture}

Canine mammary tumor cell line CMT7364 was obtained from a 13 years old dog with mammary tumor admitted to the China Agricultural University (Beijing, China), which was diagnosed as intraductal papillary carcinoma of histological grade III. The cells were cultured in DMEM medium (Gibco) supplemented with $10 \%$ fetal bovine serum (FBS, Gibco) and $1 \%$ penicillin/streptomycin, $37^{\circ} \mathrm{C}$ in a humidified atmosphere containing 5\% CO2. Till now, the cell line have already been propagated over 100 generations.

\section{Establishment of the 5-FU-resistant canine mammary tumor cell line}

5-FU-resistant cell line was established from its parental cell line CMT7364. We cultured it with a stepwise increasing concentration of 5-FU (Ruibio). The original concentration of 5-FU was $10 \mathrm{ng} / \mathrm{mL}$ and then increased by $10 \mathrm{ng} / \mathrm{mL}$ in each step till 150 $\mathrm{ng} / \mathrm{mL}$. The medium with different concentration of 5-FU was exchanged every 2 days, the cells were cultured at least 3 generations in each step. The resistant cell line was continuously cultured for 8 months, and we named it CMT7364/5-FU.

\section{Morphological observations and comparison of cell growth curves}

CMT7364 at passage 60 and CMT7364/5-FU cells in the exponential phase were observed under an inverted light microscope (Olympus).

First we portrayed the standard cell growth curve of each cell line as previously described (Sylvester 2011). Then 4000 cells per well in 96-well plate were seeded, the numbers of cells were counted using Cell Counting Kit-8 (CCK-8, Dojindo) assay each day for 7 days. Every $24 \mathrm{~h}$, after replacing the culture medium with $10 \mu \mathrm{L}$ CCK- 8 and $90 \mu \mathrm{L}$ fresh medium of three wells, the plate was cultured for additional $1.5 \mathrm{~h}$, then the optical density (OD) under $570 \mathrm{~nm}$ were tested by microplate reader (ELx808 ${ }^{\mathrm{TM}}$; BioTek). Finally, the growth curves were plotted and the population doubling time (PDT) was calculated.

\section{Chemo-sensitivity assay}

The sensitivity of CMT7364/5-FU cells (CMT7364 cells as a control) to different chemotherapeutics was detected using CCK-8 (Dojindo) assay. Briefly, the cells were treated with different concentrations of chemo-drugs 5-Fluorouracil (5-FU), Cyclophosphamide (CTX), Adriamycin (ADR), Cisplatin (DDP), Vincristine (VCR) and Methotrexate (MTX) for a period of $72 \mathrm{~h}$. After that, the culture medium was replaced with $90 \mu \mathrm{L}$ DMEM and $10 \mu \mathrm{L}$ CCK-8 for additional $1.5 \mathrm{~h}$ incubation. Then the OD values were measured at $450 \mathrm{~nm}$ on microplate reader. The resistance Factor (RF) was calculated by the ratio of the half maximal inhibitory concentration (IC50) value of CMT7364/5-FU cells to the IC50 of CMT7364 cells.

\section{Western blot assay}

Confluent cells were washed with ice-cold phosphate buffer solution (PBS) and lysed on ice in radio immunoprecipitation assay (RIPA) buffer containing protease inhibitor cocktail for $15 \mathrm{~min}$. Protein lysate was collected by centrifugation at $12,000 \times \mathrm{g}, 4^{\circ} \mathrm{C}$ for $15 \mathrm{~min}$ and the total protein concentration was determined using BCA protein assay kit (Beyotime) according to the manufacturer. Subsequently an equal amount of total proteins ( $40 \mu \mathrm{g} / \mathrm{lane})$ was loaded and separated on $10 \%$ Sodium Dodecyl Sulfate (SDS) page. Proteins were then transferred to polyvinylidene fluoride (PVDF) membrane (Millipore), blocked with $5 \%$ non-fat dry milk (BD) and probed with primary antibodies specific to ABCB1 (1:500 dilution, Bioss), ABCG2 (1:500 dilution, Bioss). The internal inference 
protein were $\beta$-actin (1:1000 dilution, Santa Cruz). Following three 5-min washes with PBST (PBS $+0.1 \%$ Tween 20 ), blots were probed with a secondary antibody in PBST (1:10000 dilution mouse anti-rabbit or 1:2000 dilution goat anti-mouse IgG-HRP); the immunoreactivity was detected using an enhanced chemiluminescence (ECL) advance western blot detection kit (Thermo).

\section{Immunocytochemical identification of $\mathrm{ABC}$ proteins expression and localization}

Cells on 24-well plate were washed with PBS, and fixed with $4 \%$ paraformaldehyde for $20 \mathrm{~min}$ at RT. Then $0.5 \%$ TritonX100-PBS was used to penetrate the cell membranes for $20 \mathrm{~min}$. After that, the cells were blocked by $1 \%$ BSA for $30 \mathrm{~min}$, and washed with PBS for three times. The cells were incubated with the primary antibodies against ABCB1 (1:500 dilution, Bioss) and ABCG2 (1:500 dilution, Bioss) at $4^{\circ} \mathrm{C}$ overnight. After washing with PBST, the cells were incubated with FITC labeled secondary antibody (1:1000 dilution, Cwbio) in dark for $1.5 \mathrm{~h}$ at RT. After washing with PBST for three times, PI was added into the plate in dark for $20 \mathrm{~min}$, and washing with PBST for three times was again performed. Finally, the cells were analyzed and photographed under a fluorescence microscope (Olympus). The mean optical density of these fluorescence signals were analyzed by image J software (Rawak sofrware, Inc. Germany).

\section{Chemosensitivity analysis in vivo}

The animal study was approved by the Institutional Animal Care and Use Committee of Chia Agricultural University. Twelve 5-week-old BALB/c female mice were divided into two groups $(\mathrm{A}, \mathrm{B})$ as the tumor bearing animals. The mice in group A were injected subcutaneously into the last mammary fat pad with $5 \times 10^{6}$ CMT7364/5-FU cells, and those in group B were injected with $5 \times 10^{6}$ CMT7364 cells. Seven days later, 5-FU $(20 \mathrm{mg} / \mathrm{kg})$ was intraperitoneally injected into the mice both in group A and group B every 3 days for 7 times. The length and width of tumors were measured by calipers once every three days. Three days after the last administration of 5-FU, the mice were sacrificed, the tumors that had been cut off were measured with caliper and weighed. Tumor volumes $(\mathrm{V})$ were calculated according to the following formula: $V=a \times b^{2} \times 1 / 2\left(\mathrm{~mm}^{3}\right)$ where $\mathrm{a}$ and $\mathrm{b}$ are the tumor length and width (in $\mathrm{mm})$, respectively.

\section{Statistical analysis}

The results are expressed as individual data or the mean \pm standard deviation (SD). Statistical comparisons were performed with Student's t test; $\mathrm{p}<0.05$ $=$ statistically significant $\left({ }^{*}\right)$ and $\mathrm{p}<0.01=$ highly statistically significant $(* *)$. The data analysis and the histogram were done with GraphPad Prism 5 (GraphPad sofrware).

\section{Results}

Establishment of CMT7364/5-FU cell line and the differences with reference to its parental cell line

The CMT7364/5-FU cell line was established after a continuous induction of 5-FU in a stepwise increasing concentration manner through 8 months. The IC50 of CMT7364 cell line and CMT7364/5-FU cell line to 5 -FU were $0.195 \pm 0.025 \mu \mathrm{g} / \mathrm{mL}$ and $2.54 \pm 0.15$ $\mu \mathrm{g} / \mathrm{mL}(\mathrm{RF}=13)$, respectively; the difference was highly statistically significant $(\mathrm{p}<0.01)$.

The cells were observed under a microscope, the differences between CMT7364 cells and CMT7364/5-FU cells are shown in Fig. 1A. CMT7364 cells tended to grow scattered but CMT7364/5-FU cells grew in clusters. The CMT7364 cells were spindle-shaped, but CMT7364/5-FU cells tended to be polygonal. Furthermore, CMT7364/5-FU cells were polynuclear. All the bars in the figures are 10 $\mu \mathrm{m}$.

The growth curve of CMT7364 cells and CMT7364/5-FU cells are shown in Fig. 1B. Both of the two cell lines had four phases, which were lag phase, exponential phase, stationary phase and decline phase. Compared to CMT7364, CMT7364/5-FU cell line indicated a slower proliferation rate. The PDT of CMT7364 cells and CMT7364/5-FU cells were $31.6 \pm 0.6 \mathrm{~h}$ and $48.6 \pm 0.3$ $\mathrm{h}$ respectively; the difference was highly statistically significant $(\mathrm{p}<0.01)$.

Five more anticancer drugs other than 5-FU were used to test the cross-resistance; they were CTX, ADR, DDP, VCR and MTX. CMT7364/5-FU cells were more resistant to the other four kinds of drugs except MTX than CMT7364 cells, too. The IC50 of ADR, DDP, CTX and VCR varied between these two cell lines; the differences were statistically significant (Fig. 2). The accurate RF of these four drugs were as follows: CTX, RF=3.45 ( $\mathrm{p}<0.01)$; $\mathrm{ADR}$, $\mathrm{RF}=3.37,(\mathrm{p}<0.05) ; \mathrm{VCR}, \mathrm{RF}=2.85,(\mathrm{p}<0.05)$ and DDP, $R F=2.68,(\mathrm{p}<0.05)$. 
A)

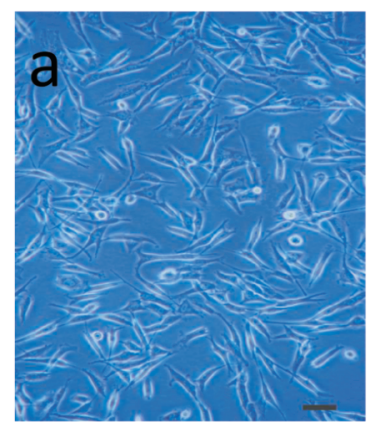

CMT7364

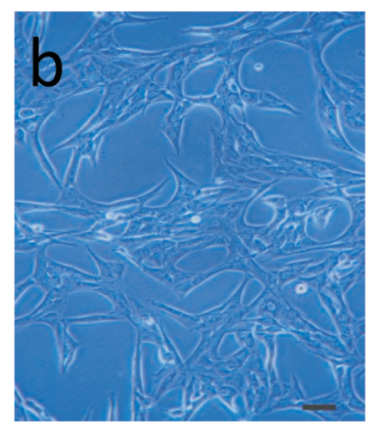

CMT7364/5-FU
B)

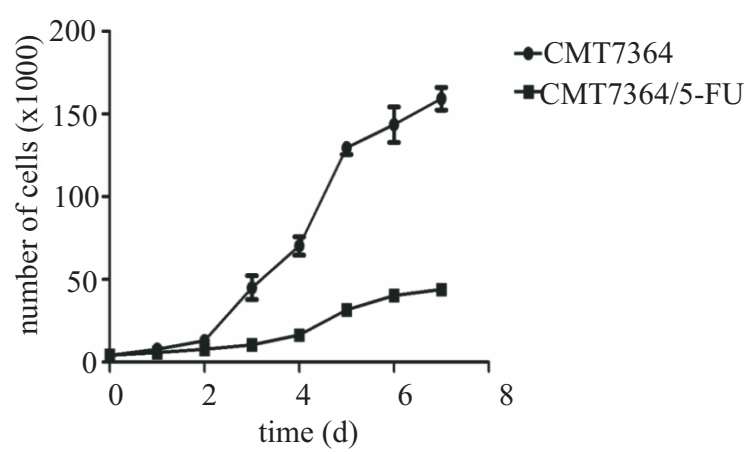

Fig. 1A. Morphological observation. CMT7364 (a) cells were scattered and spindle-shaped, CMT7364/5-FU (b) cells were clustered and polygonal; the cells tended to be polynuclear. Bar $=10 \mu \mathrm{ml}$; Fig. 1B. Growth curve of different cell lines. The proliferation rate of CMT7364/5-FU cell line was much slower than that of CMT7364 cell line. This was detected in three independent experiments. PDT $=\mathrm{T} \times \log 2 /(\log \mathrm{Nt}-\operatorname{logNo})$, where No and Nt represent the number of cells at the beginning and the end of culture period during time $\mathrm{T}$, respectively.

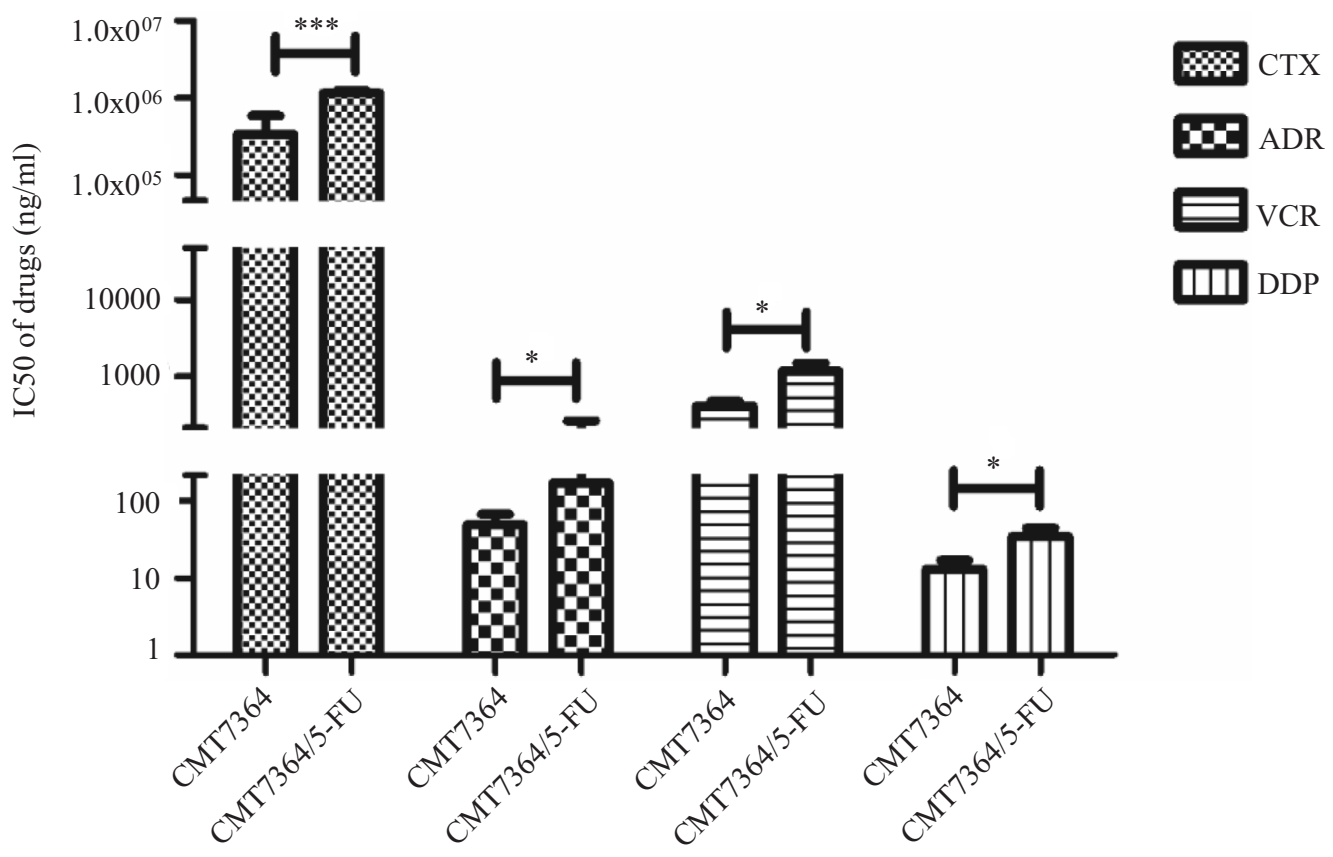

Fig. 2. As compared to CMT7364 cells, CMT7364/5-FU cells showed cross-resistance to other four chemo-drugs, i.e. Cyclophosphamide (CTX), Adriamycin (ADR), Cisplatin (DDP), Vincristine (VCR).

Western blot and immunocytochemistry were used to test the expression of $\mathrm{ABCB} 1$ and $\mathrm{ABCG} 2$ in both CMT7364 cells and CMT7364/5FU cells. The western blot results are shown in Fig. 3A, ( $\beta$-actin as internal reference). Both $\mathrm{ABCB} 1$ and $\mathrm{ABCG} 2$ were up-regulated in CMT7364/5-FU cells. Then immunocytochemistry was done to locate these two $\mathrm{ABC}$ proteins. As we can see in Fig. 3B, in accordance with western blot results, these two proteins were more intensely up-regulated in CMT7364/5-FU cells than in CMT7364 cells, and these two proteins were located mainly on the cell membrane. The mean optical density of ABCB1 in CMT7364 and CMT7364/5-FU were $0.0478 \pm 0.0003$ (/pixel) and $0.0828 \pm 0.0008$ (/pixel), respectively; the difference was highly statistically significant $(\mathrm{p}<0.01)$. The mean optical density of ABCG2 in CMT7364 and CMT7364/5-FU was $0.0501 \pm 0.0002$ (/pixel) and $0.1096 \pm 0.0008$ (/pixel), respectively; the difference was highly statistically significant $(\mathrm{p}<0.01)$. These results were shown in Fig. 3C. 
A)

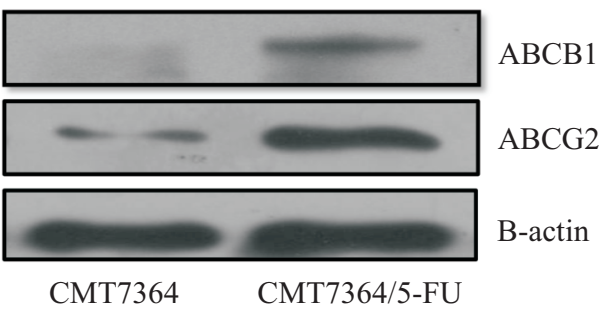

C)

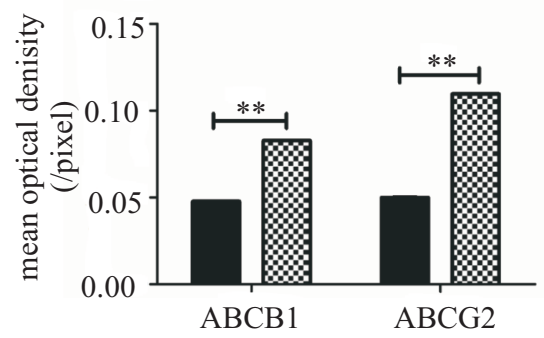

B)
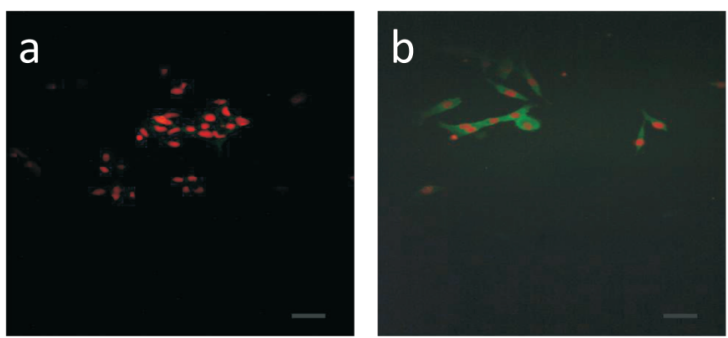

$\mathrm{ABCB} 1$

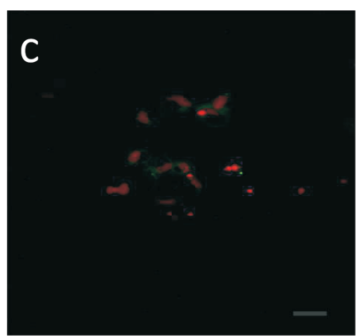

CMT7364

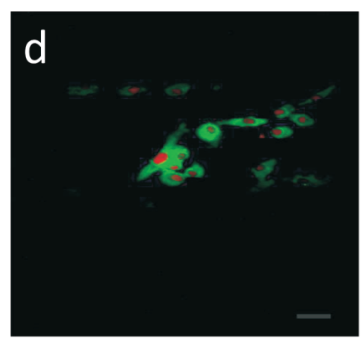

CMT7364/5-FU

Fig. 3A. Western blot assay of two main drug resistance proteins. ABCB1 in CMT7364 cells was almost no expressed and ABCG2 in CMT7364 cells exhibited low expression. On the contrary, in CMT7364/5-FU cells both ABCB1 and ABCG2 were over-expressed. $\beta$-actin as internal reference; Fig. 3B. The expression level and location of ABCB1 and ABCG2 in different kinds of cells. Red fluorescent was the nuclear that stained for PI, and green fluorescent were the protein that we tested. In CMT7364 cells the green fluorescence of ABCB1 (a) and ABCG2 (c) was very weak, but in CMT7364/5-FU cells the green fluorescence of $\mathrm{ABCB} 1$ (b) and $\mathrm{ABCG} 2(\mathrm{~d})$ was very strong. Bar $=10 \mu \mathrm{m}$; Fig. 3C. The mean optical density of the green fluorescence in Fig. 3B; the differences in $\mathrm{ABCB} 1$ and $\mathrm{ABCG} 2$ between these two cell lines were highly statistically significant $(\mathrm{p}<0.01)$.

A)

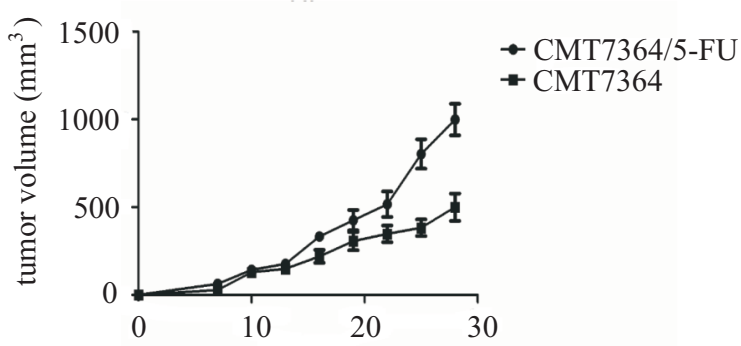

C)

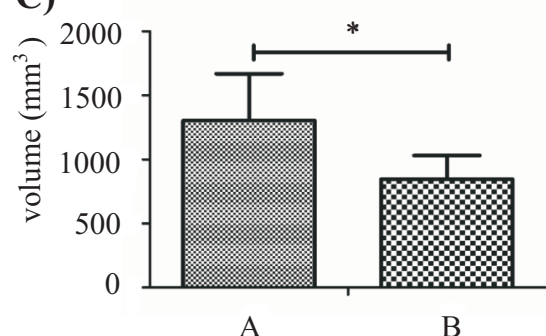

B)

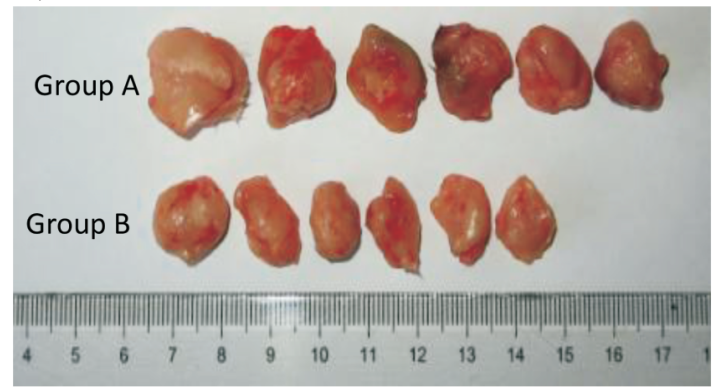

D)

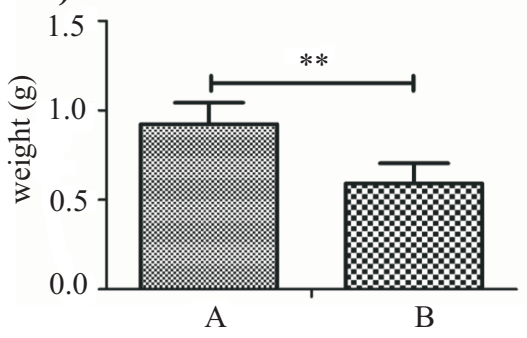

Fig. 4A. The relationship between tumor volume and time; the volume of tumors that were formed by CMT7364/5-FU cells was higher than that formed by CMT7364 cells from day 10; Fig. 4B. The volume of tumors in different groups. Group A was inoculated with CMT7364/5-FU cells, group B was inoculated with CMT7364 cells. Both of these two groups were treated with 5-FU for 21 days; Fig. 4C. The average volume of tumors in different groups in Fig B. The difference was statistically significant between group A and group B; Fig. 4D. The average weight of the tumors in different groups in Fig. B. The difference was highly statistically significant between these two groups. 


\section{CMT7364/5-FU cells were more resistant to 5-FU than CMT7364 cells in vivo}

To assess whether our findings of in vitro experiments would extended to animal models, we inoculated tumor cells into the mice to establish CMT7364 and CMT7364/5-FU xenograft mice models. The growth manner of these two kinds of cells treated with 5-FU were shown in Fig. 4A; the $\mathrm{x}$-axis were time (d) and $\mathrm{y}$-axis was tumor volume $\left(\mathrm{mm}^{3}\right)$. The volume of tumors that had been cut off was in group A $1303 \pm 823\left(\mathrm{~mm}^{3}\right)$ and in group B 845 $\pm 184\left(\mathrm{~mm}^{3}\right)$; the difference was statistically significant $(\mathrm{p}<0.05)$ (Fig. 4B and 4C). The weight of the tumors that had been cut off was in group A and group B $0.923 \pm 0.120(\mathrm{~g})$ and $0.592 \pm 0.113(\mathrm{~g})$, respectively; the difference was highly statistically significant $(p<0.01)$ (Fig. 4D). All the results revealed that in vivo CMT7364/5-FU was more resistant to 5-FU, too.

\section{Discussion}

At present, surgical treatment is nearly the only solution to treat canine mammary tumors in China. However, it stays unsatisfactory due to the consistently high mortality after the surgical resection (Kurzman et al. 1986, Bostedt et al. 1995, Wey et al. 1999, Stratmann et al. 2008). The treatment of choice for these patients is adjuvant application of cytotoxic drugs. Unfortunately, many tumor cells are, or become, resistant to chemotherapeutics. One of those hypothesis about how tumor cells acquire resistant ability was that the tumor cells might be exposed to inadequate drug concentrations because of low drug solubility, a high degree of plasma protein binding, a low level of tissue binding, a poor vascular supply and by giving insufficient doses (Lage 2008). So low concentration drug stimulating is a good way to simulate the progress of the resistance development in vitro. Forty-eight years ago the first multi-drug resistance (MDR) cell line was established in rodent cell line (Kessel et al. 1968), after that various human drug resistant cell lines have been successfully established (Iwasaki et al. 2002, Okugawa et al. 2004, Ikeda et al. 2010, Chen et al. 2013). On the contrary, no canine resistant cell line has been reported.

In the present study, a 5-FU-resistant cell line was established successfully to investigate the acquired resistance mechanism. The changes in the morphology was similar to those found in human breast cancer resistant cell line MCF-7/TAX (Chen et al. 2013). The RF value of CMT7364/5-FU cell line in comparison to CMT7364 cell line was 13, reached a moderate degree of resistance $(\mathrm{RF}=5-15 \mathrm{x})$ (Snow et al. 1991). In addi- tion, CMT7364/5-FU cells showed cross-resistance to certain widespread used chemotherapeutic drugs, including CTX, ADR, DDP and VCR. Multidrug resistance can be caused by plenty of reasons, but the over-expression of $\mathrm{ABC}$-transporters is one of the vital, especially of ABCB1 (MDR1) and ABCG2 (BCRP) for mammary tumors. In our study both of the two proteins were up-regulated in CMT7364/5-FU cell line, and located in the cell membrane probably playing a role of the efflux pump. ABCB1, originally isolated from plasma membranes of Chinese hamster ovary cells, displays a classical MDR phenotype (Juliano et al. 1976). ABCG2 is another important drug extrusion pump in mammary tumors, and it was identified by three independent studies, simultaneously (Allikmets et al. 1998, Doyle et al. 1998, Miyake et al. 1999). Many studies have revealed that ABCB1 (Thu et al. 2013, Zhang et al. 2013) and ABCG2 (Doyle et al. 2003) play important roles in breast cancer cell lines to support drug resistance. Many efforts have been made to overcome MDR by developing new drugs targeting ABCB1 and ABCG2 (Griffin et al. 2005, Mealey 2012, Zandvliet et al. 2013). Above all, $\mathrm{ABCB} 1$ and $\mathrm{ABCG} 2$ proteins play an important role in CMT7364/5-FU cell line in the development of resistance to chemo drugs.

According to the experimental results, the PDT of CMT7364/5-FU cell line was much longer than CMT7364 cell line. The proliferation rate of CMT7364/5-FU cells was much slower. Nowadays, the study of slow-cycling cells is rather actively (Chen et al. 2012, Moore et al. 2012, Roesch et al. 2013). Slow-cycling cells are subpopulations of tumor cells that grow slower, at the meantime, they can exhibit resistance to chemotherapy, leading to cancer recurrence, and even have a close association with stem cells (Ishimoto et al. 2010). We already know that 5-FU is a kind of cell cycle toxic drugs which kill high proliferation rate cells, slowing down the proliferation rate can help CMT7364/5-FU cells avoid being killed. In the study of si-ying Chen (Chen et al. 2013), as compared to its parental cell line the paclitaxel-resistance breast cancer cell line showed a prolonged PDT, too. Hence, a prolonged PDT can present another feature of resistant tumor cells.

In the present study, the resistant ability of CMT7364/5-FU in vitro has been investigated. By establishing a xenograft model, its resistant ability in vivo was explored. After treatment with 5-FU for 21 days, the volume of tumors in group A and group B showed statistically significant difference $(\mathrm{p}<0.05)$. The difference in the weight of the tumors between group A and group B was highly statistically significant $(p<0.01)$. All the results obtained further confirm that $5-\mathrm{FU}$ is a good chemo drug for treatment of ca- 
nine mammary tumor cells, and CMT7364/5-FU was much resistant to 5 -FU in vivo.

\section{Conclusion}

A 5-FU resistant canine mammary tumor cell line CMT7364/5-FU was established successfully; this cell line showed cross-resistance to other chemo-drugs, and over-expressed ABCB1 and ABCG2. CMT7364/5-FU cell line is a good model for researching the mechanism of MDR and screening effective agents to reverse drug resistance.

\section{Acknowledgements}

This work was supported by research grant No. 31372489 from the National Natural Science Foundation of China.

\section{References}

Allikmets R, Schriml LM, Hutchinson A, Romano-Spica V, Dean M (1998) A human placenta-specific ATP-binding cassette gene $(\mathrm{ABCP})$ on chromosome $4 \mathrm{q} 22$ that is involved in multidrug resistance. Cancer Res 58: 5337-5339.

Bostedt H, Tammer I (1995) Prognosis of tumors of the canine mammary-gland-a retrospective study. Praktische Tierarzt 76: 921-924.

Chen J, Li Y, Yu TS, McKay RM, Burns DK, Kernie SG, Parada LF (2012) A restricted cell population propagates glioblastoma growth after chemotherapy. Nature 488: 522-527.

Chen SY, Hu SS, Dong Q, Cai JX, Zhang WP, Sun JY, Wang TT, Xie J, He HR, Xing JF, Lu J, Dong YL (2013) Establishment of Paclitaxel-resistant Breast Cancer Cell Line and Nude Mice Models, and Underlying Multidrug Resistance Mechanisms in Vitro and in Vivo. Asian Pac J Cancer Prev 14: 6135-6140.

Choi $\mathrm{CH}$ (2005) ABC transporters as multidrug resistance mechanisms and the development of chemosensitizers for their reversal. Cancer Cell Int 5: 30.

Doyle LA, Ross DD (2003) Multidrug resistance mediated by the breast cancer resistance protein BCRP (ABCG2). Oncogene 22: 7340-7358.

Doyle LA, Yang WD, Abruzzo LV, Krogmann T, Gao YM, Rishi AK, Ross DD (1998) A multidrug resistance transporter from human MCF-7 breast cancer cells. Proc Nat Acad Sci USA 95: 15665-15670.

Griffin J, Fletcher N, Clemence R, Blanchflower S, Brayden DJ (2005) Selamectin is a potent substrate and inhibitor of human and canine P-glycoprotein. J Vet Pharmacol Ther 28: 257-265.

Honscha KU, Schirmer A, Reischauer A, Schoon HA, Einspanier A, Gaebel G (2009) Expression of ABC-Transport Proteins in Canine Mammary Cancer: Consequences for Chemotherapy. Reprod Domest Anim 44: 218-223.
Ikeda R, Vermeulen LC, Lau E, Jiang Z, Pomplun M, Kolesar JM (2010) Establishment and characterization of irinotecan-resistant human non-small cell lung cancer A549 cells. Mol Med Rep 3: 1031-1034.

Ishimoto T, Oshima H, Oshima M, Kai K, Torii R, Masuko T, Baba H, Saya H, Nagano O (2010) CD44+ ${ }^{+}$slow-cycling tumor cell expansion is triggered by cooperative actions of Wnt and prostaglandin E2 in gastric tumorigenesis. Cancer Sci 101: 673-678.

Iwasaki I, Sugiyama H, Kanazawa S, Hemmi H (2002) Establishment of cisplatin-resistant variants of human neuroblastoma cell lines, TGW and GOTO, and their drug cross-resistance profiles. Cancer Chemother Pharmacol 49: 438-444.

Juliano RL, Ling V (1976) A surface glycoprotein modulating drug permeability in Chinese hamster ovary cell mutants. Biochim Biophys Acta 455: 152-162.

Karayannopoulou M, Kaldrymidou E, Constantinidis TC, Dessiris A (2001) Adjuvant post-operative chemotherapy in bitches with mammary cancer. J Vet Med A Physiol Pathol Clin Med 48: 85-96.

Kessel D, Botteril V, Wodinsky I (1968) Uptake and Retention of Daunomycin by Mouse Leukemic Cells as Factors in Drug Response. Cancer Res 28: 938-941.

Krol M, Pawlowski KM, Majchrzak K, Mucha J, Motyl $\mathrm{T}$ (2014) Canine mammary carcinoma cell line are resistant to chemosensitizers: verapamil and cyclosporin A. Pol J Vet Sci 17: 9-17.

Kurzman ID, Gilbertson SR (1986) Prognostic factors in canine mammary tumors. Semin Vet Med Surg (Small Anim) 1: 25-32.

Lage $H$ (2008) An overview of cancer multidrug resistance: a still unsolved problem. Cell Mol Life Sci 65: 3145-3167.

Longley DB, Harkin DP, Johnston PG (2003) 5-Fluorouracil: Mechanisms of action and clinical strategies. Nat Rev Cancer 3: 330-338.

Mealey KL (2012) ABCG2 transporter: therapeutic and physiologic implications in veterinary species. J Vet Pharmacol Ther 35: 105-112.

Miyake K, Mickley L, Litman T, Zhan ZR, Robey R, Cristensen B, Brangi M, Greenberger L, Dean M, Fojo T, Bates SE (1999) Molecular cloning of cDNAs which are highly overexpressed in mitoxantrone-resistant cells: demonstration of homology to $\mathrm{ABC}$ transport genes. Cancer Res 59: 8-13.

Moore N, Houghton J, Lyle S (2012) Slow-Cycling Therapy-Resistant Cancer Cells. Stem Cells Dev 21: 1822-1830.

Nakaichi M, Takeshita Y, Okuda M, Nakamoto Y, Itamoto K, Une S, Sasaki N, Kadosawa T, Takahashi T, Taura Y (2007) Expression of the MDR1 gene and P-glycoprotein in canine mast cell tumor cell lines. J Vet Med Sci 69: 111-115.

Oguri T, Bessho Y, Achiwa H, Ozasa H, Maeno K, Maeda H, Sato S, Ueda R (2007) MRP8/ABCC11 directly confers resistance to 5-fluorouracil. Mol Cancer Ther 6: $122-127$.

Okugawa K, Kobayashi H, Hirakawa T, Sonoda T, Ogura T, Nakano H (2004) In vivo establishment and characterization of a paclitaxel-resistant human ovarian cancer cell line showing enhanced growth properties and drug-resistance only in vivo. J Cancer Res Clin Oncol 130: 178-186. 
Pawlowski KM, Mucha J, Majchrzak K, Motyl T, Krol $M$ (2013) Expression and role of PGP, BCRP, MRP1 and MRP3 in multidrug resistance of canine mammary cancer cells. BMC Vet Res 9: 119-129.

Pratt S, Shepard RL, Kandasamy RA, Johnston PA, Perry W, Dantzig AH (2005) The multidrug resistance protein 5 (ABCC5) confers resistance to 5-fluorouracil and transports its monophosphorylated metabolites. Mol Cancer Ther 4: 855-863.

Roesch A, Vultur A, Bogeski I, Wang H, Zimmermann KM, Speicher D, Koerbel C, Laschke MW, Gimotty PA, Philipp SE, Krause E, Paetzold S, Villanueva J, Krepler C, Fukunaga-Kalabis M, Hoth M, Bastian BC, Vogt T, Herlyn M (2013) Overcoming Intrinsic Multidrug Resistance in Melanoma by Blocking the Mitochondrial Respiratory Chain of Slow-Cycling JARID1B (high) Cells. Cancer Cell 23: 811-825.

Shin YK, Yoo BC, Chang HJ, Jeon E, Hong SH, Jung NS, Lim SJ, Park JG (2005) Down-regulation of mitochondrial F1F0-ATP synthase in human colon cancer cells with induced 5-fluorouracil resistance. Cancer Res 65: 3162-3170.

Snow K, Judd W (1991) Characterisation of adriamycin- and amsacrine-resistant human leukaemic $t$ cell lines. Bri J Cancer 63: 17-28.

Sosnik A (2013) Reversal of multidrug resistance by the inhibition of ATP-binding cassette pumps employing "Gen- erally Recognized As Safe" (GRAS) nanopharmaceuticals: A review. Adv Drug Deliv Rev 65: 1828-1851.

Stratmann N, Failing K, Richter A, Wehrend A (2008) Mammary tumor recurrence in bitches after regional mastectomy. Vet Surg 37: 82-86.

Sylvester P W (2011) Optimization of the Tetrazolium Dye (MTT) Colorimetric Assay for Cellular Growth and Viability. Drug Design and Discovery 716: 157-168.

Thu Phuong T, Kim H, Choi J, Na M, Jeong H (2013) Reversal of P-glycoprotein-mediated multidrug resistance is induced by mollugin in MCF-7/adriamycin cells. Phytomedicine 20: 622-631.

Tomiyasu H, Goto-Koshino Y, Fujino Y, Ohno K, Tsujimoto $\mathrm{H}$ (2014) Epigenetic regulation of the $\mathrm{ABCB} 1$ gene in drug-sensitive and drug-resistant lymphoid tumour cell lines obtained from canine patients. Vet J 199: 103-109.

Wey N, Kohn B, Gutberlet K, Rudolph R, Brunnberg L (1999) Mammary tumours in the bitch: clinical follow-up study (1995-1997). Kleintierpraxis 44: 565.

Zandvliet M, Teske E, Chapuis T, Fink-Gremmels J, Schrickx JA (2013) Masitinib reverses doxorubicin resistance in canine lymphoid cells by inhibiting the function of P-glycoprotein. J Vet Pharmacol Ther 36: 583-587.

Zhang Y, Zhou T, Duan J, Xiao Z, Li G, Xu F (2013) Inhibition of P-glycoprotein and Glutathione S-transferase-pi mediated resistance by fluoxetine in MCF-7/ADM cells. Biomed Pharmacother 67: 757-762. 